\title{
Post-Endoscopic Sphincterotomy Bleeding: Strategic Approach with Multiple Endoscopic Arms
}

\author{
Dong-Won Ahn', Seon mee Park², Joung-Ho Han² \\ 'Department of Internal Medicine, Seoul Metropolitan Government Seoul National University Boramae Medical Center, Seoul National Univer- \\ sity College of Medicine, Seoul; ${ }^{2}$ Department of Internal Medicine, Chungbuk National University College of Medicine, Cheongju, Korea
}

Endoscopic retrograde cholangiopancreatography (ERCP) is an essential method for diagnosis and treatment of various pancreatobiliary diseases and endoscopic sphincterotomy (EST) is the gateway to complete ERCP. Although techniques and instruments for EST have improved, bleeding is still the most common complication. Treatment of immediate post-EST bleeding is important because blood can interfere with subsequent procedures. Additionally, endoscopists should be cautious about delayed bleeding may cause hemobilia, cholangitis, and hemodynamic shock. Most cases of post-EST bleedings will stop spontaneously, however, endoscopic management is necessary in case of clinically significant and persistent bleeding. Various endoscopic methods including epinephrine or fibrin glue injection, electrocoagulation, hemoclipping and band ligation et al can be used through a sideviewing or forward-viewing endoscope similar to those used in hemostasis of peptic ulcer bleeding. Endoscopists who perform ERCP should use various methods of endoscopic hemostasis strategically.

Korean J Pancreas Biliary Tract 2017;22(1):14-18

Keywords: Endoscopic retrograde cholangiopancreatography, Endoscopic hemostasis, Endoscopic sphincterotomy

\begin{abstract}
Received Dec. 12, 2016
Revised Dec. 19, 2016

Accepted Dec. 22, 2016
\end{abstract}

Corresponding author: Joung-Ho Han

Department of Internal Medicine, Chungbuk National University College of Medicine, 1 Chungdae-ro, Seowon-gu, Cheongju 28644, Korea Tel. +82-43-269-6802 Fax. +82-43-273-3252 E-mail; joungho@cbnu.ac.kr

This is an Open Access article distributed under the terms of the Creative Commons Attribution Non-Commercial License (http:/ creativecommons.org/licenses/by-nc/3.0/) which permits unrestricted non-commercial use, distribution, and reproduction in any medium, provided the original work is properly cited.

Copyright $(92017$ by The Korean Journal of Pancreas and Biliary Tract

\section{서 론}

내시경유두괄약근절개술(endoscopic sphincterotomy, EST) 은 내시경역행담췌관조영술(endoscopic retrograde cholangiopancreatography, ERCP)로 담췌관 질환을 진단하고 치료하기 위한 필수적인 관문이다. 하지만 췌장염, 출혈, 담관염, 장천공 등의 합병증이 발생할 수 있어 항상 주의가 필요하다. 전체적인
시술 합병증 발생률은 $4-10 \%$ 정도이며, 치명적인 경우는 $0.5 \%$ 미만으로 알려져 있다. ${ }^{1}$ EST 후 발생한 출혈(post-EST bleeding)은 정의를 어떻게 하느냐에 따라 $1-48 \%$ 의 다양한 발생률 을 보인다. 출혈은 그 자체도 무서운 합병증이지만, 지혈술 과 정에서 췌장염 또는 천공 등의 추가적인 합병증을 유발할 수 있 으므로 더욱 주의가 필요하다. 이에 본고에서는 post-EST 출혈 의 내시경적 지혈을 중심으로 다루려고 한다. 


\section{본 론}

\section{Post-EST 출혈의 분류와 역학}

Post-EST 출혈의 대부분은 약간의 울혈성 출혈이며 다행히 도 대부분 저절로 멎기 때문에 임상적으로 큰 어려움을 유발 하지는 않는다. ${ }^{3}$ 그러나 동맥성이나 대량출혈이 간혹 발생하 게 되면 내시경 시야를 가리게 되므로, 지혈술에도 곤란을 겪 으며 ERCP 시술의 목적을 달성하지도 못하게 된다. 시술 후 출혈의 정도는 Cotton ${ }^{4}{ }^{4}$ 의 제시한 다음과 같은 분류가 주로 사용되고 있다. 경증(mild)은 혈중 헤모글로빈이 $3 \mathrm{~g} / \mathrm{dL}$ 미만 으로 떨어지고 수혈이 필요 없는 경우이고, 중등증(moderate)은 4 유닛 이하의 수혈이 필요하지만 혈관조영술이나 수 술이 필요하지 않은 경우이며, 증증(severe)은 5 유닛 이상의 수혈이 필요하거나 중재적 치료(혈관조영술이나 수술)가 필 요한 경우이다(Table 1). ${ }^{4}$ 출혈이 발생한 시기에 따라 분류할 수도 있는데, 출혈이 발생한 시기에 따라 시술 중 발생한 즉각 (immediate) 또는 조기 (early) 출혈과 시술 후 수 시간 또는 수 일이 지나 발생하는 지연(delayed) 출혈로 분류된다. ${ }^{2,45}$ 과거 에는 혈색소 감소가 동반될 정도의 출혈이 $2-5 \%$ 빈도로 보고 되었지만, 최근의 연구에서는 $1-2 \%$ 감소된 빈도로 보고하고 있다. ${ }^{6-8}$ 이러한 원인은 명확히 제시되고 있지는 않지만, papillotome을 비롯한 ERCP 부속기구의 발전과 출혈위험군에 대한 사전 조치 등이 가능한 원인으로 고려될 수 있다.

\section{2. 출혈의 위험인자}

Post-EST 출혈의 위험인자로는 환자측 인자, 해부학적 인 자, 기술적 인자로 분류할 수 있다. Freeman 등 ${ }^{5}$ 은 여러 연구 결과에 따라 위험인자 분류를 크게 확정적(definite; 대부분의 연구들의 다변량 분석에서 의미를 가짐), 가능성 있는(maybe; 여러 연구들의 단변량 분석에서 의미) 그리고 관련 없음 (no; 의미 있는 결과를 보인 연구 결과가 없었던 경우) 세 가 지로 분류하였다(Table 2). 확정적 인자들에는 출혈경향이 있 는 환자, 3 일 이내에 항응고제 사용, 시술 전 담관염, EST 도 중 출혈, 시술 의사의 경험이 적은 경우를 제시하였고, 가능성
있는 인자들로는 간경변, 확장된 총담관, 유두부 주위의 게실, 예비괄약근 절개술, 담도담석이 있는 경우이며, 아스피린과 비스테로이드성 소염제의 사용, 유두부 종양, 괄약근 절개 길 이나 추가적인 절개술은 출혈에 영향을 주지 않았다.

상기의 위험인자들 중 환자 측 또는 해부학적인 위험인자 가 있는 경우에는 $\mathrm{ERCP}$ 의 경험이 충분한 시술자가 시행하여 기술적인 측면에서의 위험을 줄이는 것이 의미가 있을 것이 다. 또한 혈소판 수가 낮거나, 간경변 등의 이유로 프로트롬빈 시간이 증가된 환자는 혈소판 수혈이나 신선동결혈장 및 비 타민 $\mathrm{K}$ 를 투여하는 준비가 필요하다. 혈액응고장애가 의심되 는 담관결석 환자에서는 EST와 비교하여 출혈의 발생이 적다 고 알려진 유두부 풍선확장술을 고려할 수 있다. ${ }^{9-11}$ 항응고제 사용에 따른 준비는 미국소화기내시경학회(American Society of Gastrointestinal Endoscopy)의 가이드라인을 따르는 것을 권고한다. ${ }^{12}$

\section{3. 내시경 지혈술의 종류와 방법}

내시경적 지혈술에는 주사침을 이용한 주입법, 열응고술을 이용한 방법, 압박이나 클립 등을 이용한 기계적 방법이 있다. 상황에 따라 내시경 치료법의 선택은 다를 수 있으며, 순차적 으로 이용될 수 있다. 그리고 내시경 치료에 실패한 경우에 혈 관조영술을 이용한 색전술과 수술도 고려할 수 있다.

\section{1) 주사침을 이용한 주입법(injection therapy)}

희석된 에피네프린을 절개한 부위와 그 주변에 주사침을 이용하여 주입하는 지혈술이 가장 많이 사용되어 왔다. 에피 네프린은 $1: 10,000$ 으로 희석하여 주입하며, 치료 효과에 대하 여 96-100\%로 보고되기도 하였다. ${ }^{6}$ 주의해야 할 점으로는 첫 째, 측시경의 특성으로 주사침이 내시경 선단 부위를 통과하 며 피막을 딿고 내시경 채널을 손상할 수 있으므로 주의가 필 요하며, 둘째, 에피네프린의 전신 흡수에 따른 심장 발작의 가 능성을 유의하여야 한다. ${ }^{13}$

최근 에피네프린 주입으로 지혈이 실패한 경우에 피브린 글루(fibrin glue)를 주입하여 지혈에 성공한 보고들이 있

Table 1. Grading system for the major complications of ERCP and endoscopic sphincterotomy ${ }^{4}$

\begin{tabular}{llll}
\hline & \multicolumn{1}{c}{ Mild } & Moderate & Severe \\
\hline Bleeding & $\begin{array}{c}\text { Clinical (i.e., not just endoscopic) evidence } \\
\text { of bleeding. Hemoglobin drop }<3 \mathrm{~g} / \mathrm{dL}, \\
\text { and no need for transfusion }\end{array}$ & $\begin{array}{l}\text { less), no angiographic intervention or } \\
\text { surgery }\end{array}$ & $\begin{array}{c}\text { Transfusion, } 5 \text { units or more, or intervention } \\
\text { (angiographic or surgical) }\end{array}$ \\
\hline
\end{tabular}

ERCP, endoscopic retrograde cholangiopancreatography. 
Table 2. Risk factors for hemorrhage after sphincterotomy in the univariate and multivariate analysis ${ }^{4}$

\begin{tabular}{llll}
\hline \multicolumn{1}{c}{ Definite } & \multicolumn{1}{c}{ Maybe } & \multicolumn{1}{c}{ No } \\
\hline Risk factor & Coagulopathy & Cirrhosis & Acetylsalicylic acid or nonsteroid anti- \\
inflammatory drug use & Ampullary tumor \\
& Anticoagulation within 3 days of EST & Dilated CBD & Longer length of EST \\
& Bleeding during initial EST & Periampullary diverticulum & Extension of prior EST \\
& Lower endoscopist & CBD stone & \\
\hline
\end{tabular}

EST, endoscopic sphicterotomy; ERCP, endoscopic retrograde cholangiopancreatography; CBD, common bile duct.

다. ${ }^{14,15}$ 가능한 지혈법이기는 하지만 EST 후 발생한 출혈에 있 어서는 췌관의 입구를 막아 췌장염이 발생할 수 있으므로 췌 장염을 예방하기 위하여 미리 췌관에 스텐트가 삽입되어 있 다면 고려해 볼 수 있다.

\section{2) 열 응고법(thermal coagulation)}

출혈하는 혈관에 열을 가하여 조직의 부종과 단백질 변성, 혈관 수축 등에 의하여 지혈을 일으키는 열응고법에는 전기 나 빛 에너지를 이용하여 간접적으로 열을 발생시키는 전기 응고법, 아르곤 플라즈마 응고법 및 레이저 응고법 등이 있 다. ${ }^{16}$ 이러한 열 응고법을 post-EST 출혈의 지혈에도 사용해 왔다. ${ }^{17,18} \mathrm{EST}$ 에 사용한 표준형 절개도를 그대로 사용하여 응 고파를 내보내어 지혈에 사용할 수도 있지만, 다량의 출혈에 는 효과적이지 않다. 열 응고법에 사용되는 기구(devices)는 대부분 상부 위장관 내시경 지혈술에 사용하는 것과 같다. 크 게 도자(probe)형과 겸자(forcep)형이 있으며, 여러 제조사에 서 공급하고 있다. 도자형은 출혈 부위에 전극을 접속하고 열 을 가하는 방식으로 용종절제술용 올가미(polypectomy snare)를 대용으로 사용하기도 한다. 간편하게 사용하기 좋다 는 장점이 있지만, 열이 전달되는 깊이와 범위가 환자의 장움 직임이나 호흡에 따라 크게 변할 수 있고, 출혈되는 혈관을 더 깊게 파고 들어가서 더 큰 출혈을 일으킬 수 있으므로 응고파 를 보내는 시간을 짧게 유지해야 하고 시술자의 숙련이 필요 하다. 겸자형의 경우 출혈되는 혈관을 잡고 응고파를 내보내 므로 정확하고 한정된 부위로만 열이 가해지는 장점이 있지 만, $\mathrm{ERCP}$ 에 사용되는 측시경의 구조적 특성으로 인하여 보 이는 화면의 상방(해부학적으로 근위부)의 출혈 부위에 접근 이 어렵고, 조준 또한 쉽지 않다. 이러한 어려움은 아르곤 플 라즈마 응고법을 사용할 때도 마찬가지이다. ${ }^{19,20}$ 출혈 부위의 해부학적 위치와 확보되는 시야에 따라 두 가지 형태의 기구 를 적절히 사용할 수 있다면 더 좋은 치료 결과를 낼 것이다. 열 응고법을 사용하기 전에 주사침을 이용한 주입법으로 지 혈을 유도하거나, 대량 출혈의 경우에 시야를 확보하는데 도
움을 받을 수 있다. 십이지장경으로 접근이 어려운 경우 직시 경으로 바꾸거나 직시경 선단부에 캡(cap)을 씨어 접근을 시 도하면 도움이 될 수 있다. ${ }^{21-23}$ 특히, 유두부 주위의 게실이 있 거나 주변에 유착이 있는 경우 등에서 직시경으로 유두부에 접근을 하면 확연히 좋은 시야를 얻는 경우가 있으므로 측시 경으로 계속 지혈에 실패하는 경우 직시경으로 바꿔볼 수 있 다.

\section{3) 기계적 지혈(mechanical hemostasis)}

기계적인 지혈법으로 시술 중 발생한 출혈에 대하여 풍선 을 이용한 압박이 도움이 될 수 있다는 과거 고찰에서 설명이 있고, 임상에서도 많은 시술의들이 담석제거용 풍선을 이용 하여 출혈이 있는 유두부에 압박을 하는 지혈법을 사용하고 있다. ${ }^{24}$ 하지만, 이에 대한 효과를 전향적으로 연구한 문헌은 찾을 수 없으며, 개인적 경험에 의존한 것으로 보인다. 정맥에 서의 울혈성 출혈은 이러한 풍선압박으로 지혈이 될 수 있겠 지만, 이는 압박 없이도 자연 지혈될 수도 있는 출혈일 수도 있다. 대표적인 기계적 지혈법은 상부 및 하부 위장관 출혈에 많이 사용되어 온 내시경 클립이 post-EST 출혈에도 사용될 수 있다. ${ }^{25,26}$ 그러나 EST 후 발생한 출혈의 지혈을 위해 클립 을 사용하는 경우 응고도자보다 더 출혈 부위에 적절한 접근 이 어려우며, 클립이 측시경의 elevator를 지나면서 접히는 문 제도 종종 생긴다. 그리고 잘못 결찰되거나 장내에 남겨진 클 립이 지혈술을 방해하는 등의 문제도 생길 수 있으므로 주의 가 필요하다. 식도정맥류 또는 위장관 출혈 지혈의 목적으로 사용되는 내시경 밴드결찰술도 성공적인 지혈 치료로 이용한 보고는 있지만, 췌장염과 담관 폐쇄의 위험이 높으므로 주의 가 필요하다. ${ }^{27}$ 최근 몇몇 보고에서 피막형 금속관(covered metal stent)을 총담관에 임시로 삽입하여 출혈 부위를 압박 함으로써 효과적인 지혈을 보고하였다. 하지만 피막형 금속 관이 고비용이 든다는 점과 다시 스텐트를 제거해야 불편함 이 있으므로 에피네프린 주입 등 다른 치료가 실패하거나 용 이치 않을 경우 시도해 볼 수 있다. ${ }^{28,29}$ 


\section{4. 혈관조영술 또는 수술적 지혈}

혈관조영술을 통한 지혈술과 수술은 내시경 치료로 성공하 지 못한 출혈에 대하여 비슷한 효과를 보고하고 있다. ${ }^{30,31}$ 최 근 복강경 수술의 발전으로 과거에 비하여 수술시간과 합병 증의 변화가 있지만, 십이지장 유두부는 후복막에 위치한 기 관으로 수술적 접근이 비교적 어려운 위치이다. 혈관조영술 에 의한 색전술 또한 발전을 하여 $83-100 \%$ 의 지혈 성공률을 보이고 있다. ${ }^{1,31}$ 따라서 수술에 비하여 덜 침습적인 혈관조영 술을 신속하게 시행할 수 있다면 환자의 상황에 따라 수술보 다 먼저 고려할 수 있다.

\section{결 론}

Post-EST 출혈은 드물지만 때론 심각한 문제가 발생할 수 있으며 적절한 지혈이 실패하는 경우 환자의 생명을 위협할 수 있다. 출혈을 완전히 예측할 수 없지만 위험인자에 대해 잘 알고 있어야 post-EST 출혈을 최소화할 수 있다. 출혈에 대해 내시경 지혈술을 시행할 경우 시술 자체에 의한 장천공, 췌장 염 등의 합병증도 발생할 수 있으므로 시술자는 다양한 내시 경 지혈술에 대해 잘 알고 상황에 따라 적절하게 시행할 수 있 어야 한다. 지혈술로 인한 천공(지연형 천공을 포함한) 및 췌 장염을 예방하기 위하여 가능한 담관 및 췌관에 스텐트가 삽 입하는 것이 바람직하다. 그리고 위에 열거한 다양한 내시경 지혈법을 해부학적 위치와 환자의 상태를 고려하여 순차적으 로 시행할 수 있다. 또한 최근 피막형 금속관 삽입에 의한 지 혈술이 높은 성적으로 보고되고 있으므로 상황에 따른 고려 가 필요하다. 그리고 내시경 지혈이 어렵거나 실패한 경우 과 다 출혈에 의한 저혈량 쇼크를 막기 위해 적극적인 수액공급 과 수혈은 물론 혈관조영술이나 수술 치료가 신속하게 이루 어 질 수 있도록 다학제 간 긴밀한 협조가 필요하다.

\section{요 약}

내시경역행담췌관조영술(ERCP)은 췌담도 질환의 진단과 치료에 필수적인 시술이며, 내시경유두괄약근절개술(EST)은 $\mathrm{ERCP}$ 를 성공하기 위한 관문이다. $\mathrm{EST}$ 를 시행하기 위한 장비 의 발전에도 불구하고, EST 후 발생한 출혈은 여전히 치명적 인 합병증으로 남아있다. EST 직후에 발생한 출혈은 내시경 시야를 방해하여 성공적인 $\mathrm{ERCP}$ 를 마칠 수 없게 하며, EST 후 지연형 출혈의 경우에는 혈담즙과 이에 의한 담도염, 심지
어 혈역학적 쇼크까지 유발할 수 있으므로 주의가 필요하다. 다행히도 대부분의 출혈은 자발적으로 멈추지만, 임상적으로 의미 있는 출혈량이 있거나, 지속적인 출혈에서는 1 차적으로 내시경 지혈술이 필요하다. 에피네프린을 혼합한 식염수의 주 사, 전기응고법, 클립이나 밴드를 이용한 기계적 지혈법까지 다양한 내시경적 지혈법이 있으며, 이러한 방법은 대부분 위 장관 출혈의 지혈술에서 사용되는 방법을 가져온 것이다. $\mathrm{ERCP}$ 를 시행하는 의사는 다양한 내시경적 지혈술을 모두 숙 지하고 있어야, 한가지 지혈술로 실패한 경우에 다른 방법의 지혈술로 전환을 할 수 있어야한다. 또한 내시경적 지혈술에 실패한 경우에는 혈관조영술이나 수술로 출혈을 치료할 수 있 는 결정을 할 수 있어야만 한다.

국문 색인: 내시경역행담췌관조영술, 내시경지혈술, 내시경 유두괄약근절개술

\section{REFERENCES}

1. ASGE Standards of Practice Committee, Chandrasekhara V, Khashab MA, et al. Adverse events associated with ERCP. Gastrointest Endosc 2017:85:32-47.

2. Ferreira LE, Baron TH. Post-sphincterotomy bleeding: who, what, when, and how. Am J Gastroenterol 2007;102:2850-2858.

3. Andriulli A, Loperfido S, Napolitano G, et al. Incidence rates of postERCP complications: a systematic survey of prospective studies. Am J Gastroenterol 2007;102:1781-1788.

4. Cotton PB, Lehman G, Vennes J, et al. Endoscopic sphincterotomy complications and their management: an attempt at consensus. Gastrointest Endosc 1991;37:383-393.

5. Freeman ML, Nelson DB, Sherman $\mathrm{S}$, et al. Complications of endoscopic biliary sphincterotomy. N Engl J Med 1996;335:909-918.

6. Leung JW, Chan FK, Sung JJ, Chung S. Endoscopic sphincterotomyinduced hemorrhage: a study of risk factors and the role of epinephrine injection. Gastrointest Endosc 1995;42:550-554.

7. Christensen M, Matzen P, Schulze S, Rosenberg J. Complications of ERCP: a prospective study. Gastrointest Endosc 2004;60:721-731.

8. Wang P, Li ZS, Liu F, et al. Risk factors for ERCP-related complications: a prospective multicenter study. Am J Gastroenterol 2009;104:31-40.

9. Yang XM, Hu B. Endoscopic sphincterotomy plus large-balloon dilation vs endoscopic sphincterotomy for choledocholithiasis: a metaanalysis. World J Gastroenterol 2013;19:9453-9460.

10. Park DH, Kim MH, Lee SK, et al. Endoscopic sphincterotomy vs. endoscopic papillary balloon dilation for choledocholithiasis in patients with liver cirrhosis and coagulopathy. Gastrointest Endosc 2004;60:180-185. 
11. Jin PP, Cheng JF, Liu D, Mei M, Xu ZQ, Sun LM. Endoscopic papillary large balloon dilation vs endoscopic sphincterotomy for retrieval of common bile duct stones: a meta-analysis. World J Gastroenterol 2014; 20:5548-5556.

12. ASGE Standards of Practice Committee, Acosta RD, Abraham NS, et al. The management of antithrombotic agents for patients undergoing GI endoscopy. Gastrointest Endosc 2016;83:3-16.

13. von Delius $S$, Thies $P$, Umgelter $A$, Prinz C, Schmid RM, Huber W. Hemodynamics after endoscopic submucosal injection of epinephrine in patients with nonvariceal upper gastrointestinal bleeding: a matter of concern. Endoscopy 2006;38:1284-1288.

14. Mutignani M, Seerden T, Tringali A, et al. Endoscopic hemostasis with fibrin glue for refractory postsphincterotomy and postpapillectomy bleeding. Gastrointest Endosc 2010;71:856-860.

15. Born P, Ott R, Rösch T. Endoscopic hemostasis using fibrin sealant for postsphincterotomy bleeding: report of two cases. Gastrointest Endosc 2000;51:731-733.

16. Savides TJ, Jensen DM. Therapeutic endoscopy for nonvariceal gastrointestinal bleeding. Gastroenterol Clin North Am 2000;29:465-487, vii.

17. Sherman S, Hawes RH, Nisi R, Lehman GA. Endoscopic sphincterotomy-induced hemorrhage: treatment with multipolar electrocoagulation. Gastrointest Endosc 1992;38:123-126.

18. Kuran S, Parlak E, Oguz D, Cicek B, Disibeyaz S, Sahin B. Endoscopic sphincterotomy-induced hemorrhage: treatment with heat probe. Gastrointest Endosc 2006;63:506-511.

19. Oviedo JA, Barrison A, Lichtenstein DR. Endoscopic argon plasma coagulation for refractory postsphincterotomy bleeding: report of two cases. Gastrointest Endosc 2003;58:148-151.

20. Katsinelos P, Kountouras J, Chatzimavroudis G, et al. Endoscopic hemostasis using monopolar coagulation for postendoscopic sphincterotomy bleeding refractory to injection treatment. Surg Laparosc Endosc Percutan Tech 2010;20:84-88.

21. Leal-Salazar JA, Gonzalez-Gonzalez JA, Garza-Galindo AA, Maldonado-Garza HJ, Flores Rendón AR, Mar Ruiz MA. Use of a gastroscope armed with a transparent cap in the treatment of bleeding after endoscopic sphincterotomy. Endoscopy 2009;41 Suppl 2:E91.

22. Choi YR, Han JH, Cho YS, et al. Efficacy of cap-assisted endoscopy for routine examining the ampulla of Vater. World J Gastroenterol 2013;19:2037-2043.

23. Liu F, Wang GY, Li ZS. Cap-assisted hemoclip application with forward-viewing endoscope for hemorrhage induced by endoscopic sphincterotomy: a prospective case series study. BMC Gastroenterol 2015;15:135.

24. Rustagi T, Jamidar PA. Endoscopic retrograde cholangiopancreatography-related adverse events: general overview. Gastrointest Endosc Clin N Am 2015;25:97-106.

25. Baron TH, Norton ID, Herman L. Endoscopic hemoclip placement for post-sphincterotomy bleeding. Gastrointest Endosc 2000;52:662.

26. Lin LF, Siauw CP, Ho KS, Tung JN. Hemoclip treatment for post-endoscopic sphincterotomy bleeding. J Chin Med Assoc 2004;67:496-499.

27. Kang MH, Jeong JW, Han JH. Successful hemostasis by using endoscopic band ligation for uncontrolled postendoscopic sphincterotomy bleeding. Gastrointest Endosc 2014;79:336-337.

28. Itoi T, Yasuda I, Doi S, Mukai T, Kurihara T, Sofuni A. Endoscopic hemostasis using covered metallic stent placement for uncontrolled post-endoscopic sphincterotomy bleeding. Endoscopy 2011;43:369372.

29. Canena J, Liberato M, Horta D, Romão C, Coutinho A. Short-term stenting using fully covered self-expandable metal stents for treatment of refractory biliary leaks, postsphincterotomy bleeding, and perforations. Surg Endosc 2013;27:313-324.

30. Maleux G, Bielen J, Laenen A, et al. Embolization of post-biliary sphincterotomy bleeding refractory to medical and endoscopic therapy: technical results, clinical efficacy and predictors of outcome. Eur Radiol 2014;24:2779-2786

31. So YH, Choi YH, Chung JW, Jae HJ, Song SY, Park JH. Selective embolization for post-endoscopic sphincterotomy bleeding: technical aspects and clinical efficacy. Korean J Radiol 2012;13:73-81. 